axilla with thin polyethylene film held in place with cotton-wool balls and crêpe bandage. After using this irksome regimen for six months one patient reported that control of sweating was achieved just as readily without occlusion. Accordingly we instructed our patients to apply the solution without an occlusive dressing, and subsequent experience showed that this element of Shelley and Hurley's method is unnecessary. The morning after application the axilla was washed thoroughly with soap and water. Nightly applications were continued for one week, after which the patient applied the solution only when necessary.

\section{Results}

All the patients were followed up closely in the two departments, and after 12 months a questionnaire was sent to the Swindon group asking for their comments. Sixty-four patients were highly delighted with the treatment and had achieved complete control of axillary sweating by periodic use of the solution. We felt that the high rate of return of the questionnaire in Swindon (41 out of 42 returned in two weeks) also reflected their satisfaction. After the initial period of nightly treatment the interval between applications varied from two days to one year. Most patients, however, had to apply the solution once every seven to 21 days to maintain control. The only side effect mentioned was irritation of the axillary skin, which we presume is caused by the high acidity of the solution. Twenty-nine experienced some irritation, but 28 of these said that it was readily relieved by applying $1^{\circ}$ " hydrocortisone cream on the morning after treatment. Some of these patients also found that they could reduce the irritation by applying the solution more accurately to the area of excessive sweating. One patient, who had the least severe hyperhidrosis, had to stop treatment because of unbearable irritation.

\section{Discussion}

This trial was highly successful, and we think that $20^{\circ}$ \% aluminium chloride hexahydrate in absolute alcohol should be considered to be the treatment of first choice in axillary hyperhidrosis. In particular, the troublesome occlusive dressing recommended by Shelley and Hurley ${ }^{7}$ was found to be unnecessary, which makes the treatment much more acceptable to the patient. Preparation of the solution has been described as laborious, ${ }^{11}$ but this has not been our experience. Our hospital pharmacists report that if the mixture of aluminium chloride hexahydrate crystals and absolute alcohol is left at room temperature and shaken occasionally a $20 \%$ solution may be produced in three weeks. A local chemist has also made the solution without difficulty. Using absolute alcohol means paying excise duty, which increases the cost of the preparation. Thus we now use a lower-proof spirit $(95-99.5 \%)$, and initial results indicate no diminution of effect.

Irritation of the axilla was the only side effect reported and was almost always readily relieved by $1 \%$ hydrocortisone cream. Most of the patients were so delighted with the control of their sweating that they would tolerate minor irritation for a few hours every fortnight. Although the solution was highly acidic, we received no complaints of damage to clothing. Nevertheless, one patient reported total destruction of his passport when the bottle broke in his suitcase.

We are now extending our work to include excessive sweating at other sites and have had similar encouraging results with sweat reduction on the palms and soles and, in one patient, the forehead. We are reporting these results as early as possible because we think that there is no longer any indication for surgical treatment of axillary hyperhidrosis and that such operative procedures should be avoided.

\section{References}

1 Cunliffe, W J, and Tan, S G, Practitioner, 1976, 216, 419.

2 Greenhalgh, R M, Rosengarten, D S, and Martin, P, British Medical fournal, 1971, 1, 332

${ }^{3}$ Hurley, H J, and Shelley, W B, Fournal of the American Medical Association, 1963, 196, 109

4 Jemec, B, Scandinavian fournal of Plastic and Reconstructive Surgery, 1975, 9,44

${ }^{5}$ Ashby, E C, and Williams, J Ll, British Medical fournal, 1976, 2, 1173.

${ }^{6}$ Ellis, H, British Medical fournal, 1977, 2, 301.

Shelley, W B, and Hurley, H J, Acta Dermato-venereologica, 1975, 55, 241.

Papa, C M, and Kligman, A M, fournal of Investigative Dermatology, 1967, 49, 139.

${ }^{9}$ Gordon, B I, and Maiback, H I, Fournal of Investigative Dermatology, 1968, 50, 411 .

10 Sneddon, I B, British Medical fournal, 1976, 2, 1447.

${ }^{11}$ Ryan, T J, Medicine, 1977, 32, 1871.

\title{
Proctocolectomy without ileostomy for ulcerative colitis
}

\author{
A G PARKS, R J NICHOLLS
}

British Medical fournal, 1978, 2, 85-88

\section{Summary and conclusions}

An operation has been developed that permits total removal of all disease-prone mucosa in ulcerative colitis but avoids the need for a permanent ileostomy. The colon and upper half of the rectum are excised and the remaining inflamed mucosa is stripped from the rectal stump down to the dentate line of the anal canal. A pouch is fashioned from a triplicated loop of terminal ileum.

\footnotetext{
St Mark's Hospital, London EC1V 2PS and London Hospital, London E1 2AD

Sir ALAN G PARKS, FRCS, FRCP, consultant surgeon

R J NICHOLLS, MCHIR, FRCS, senior surgical registrar
}

This is drawn down through the denuded rectum and an anastomosis created, via the per-anal approach, between the ileum just distal to the pouch and the mid-anal canal. A temporary ileostomy is made.

Out of eight patients so treated, five were available for assessment, and four of them were highly satisfied with the result in improved health and function. The remaining three were awaiting closure of their ileostomies.

\section{Introduction}

Ulcerative colitis is of unknown aetiology, and its treatment, both medical and surgical, is empirical. Operative treatment will remain an essential part of management until the cause of the disease is found and a specific cure discovered. Proctocolectomy is the commonest procedure used and eliminates colonic mucosa in its entirety and thus the source of inflammation and potential malignancy. The price paid, however, is a permanent ileostomy. 
Various alternative procedures have been tried, either to improve the quality of life for a patient with an ileostomy or remove the need for a stoma altogether. Of these, both colectomy with ileorectal anastomosis and the Kock continent ileostomy reservoir have won places in clinical practice. Each, however, has disadvantages. ${ }^{1-5}$ For ileorectal anastomosis most surgeons select patients according to strict criteria, ${ }^{4}$ thus limiting its application. Furthermore, leaving part of the inflamed mucosa may result in persistent disease, sometimes with severe exacerbations, and the risk of malignant change. ${ }^{4-7}$ The Kock procedure carries a morbidity and mortality and still includes an abdominal stoma. The technical problems of making an inverted nipple valve have been largely responsible for complications requiring reoperation in nearly a third of the cases. ${ }^{12}$

Several attempts have been made to combine colectomy with removal of the inflamed mucosa from the rectum and preserve intestinal continuity. ${ }^{8-10}$ These methods have not been generally accepted, however, because of unpredictable or unacceptable functional results. After an ileoanal anastomosis, for example, fewer than half the patients obtained satisfactory function. ${ }^{8}$

Two avenues of advance have now converged to allow a fresh approach to be made to this problem. The first is the work of Kock, ${ }^{311}$ who has shown that an ileal pouch is consistent with normal intestinal function. The second is a resurgence of interest in anorectal physiology, which has already enabled advances in surgical technique to take place. In particular, it has been shown that in such conditions as haemangioma of the rectum $^{12}$ and extensive villous tumours of the rectum ${ }^{13}$ the colon may be introduced through the rectum denuded of its mucosa and anastomosed to the anal canal with satisfactory functional results. Rectal sensation is normal after these procedures and the anorectal reflex mechanisms remain intact. It was therefore a reasonable assumption that if an ileal pouch was used instead of the colon, normal sensation would be experienced as it filled and the anorectal sphincter mechanism would maintain continence.

\section{Operative technique}

The operation may be considered in two parts. The first consists in total resection of the colon and upper rectum with the removal of all remaining rectal mucosa. In the second, an ileal pouch is fashioned and anastomosed to the anal canal per-anally. ${ }^{14} \mathrm{~A}$ loop-defunctioning ileostomy is made to protect this anastomosis.

The patient is placed in the position used for synchronous combined excision of the rectum, with the legs raised. Through a long left paramedian incision the entire colon is mobilised as for a total colectomy to include the rectum to a point in its middle third, just below the peritoneal reflection. The dissection is kept close to the viscus to avoid damaging the pelvic autonomic nerves. The ileum is divided just proximal to the ileocaecal valve; the rectum is transected, leaving a distal segment about $8 \mathrm{~cm}$ long, and the colon and upper rectum are removed routinely.

The ileal pouch is then constructed from the terminal $30 \mathrm{~cm}$ of the small intestine; the terminal $5 \mathrm{~cm}$ is left untouched to act as a conduit. The $25 \mathrm{~cm}$ segment is opened on its antimesenteric border and folded three times (fig 1). A continuous stitch of $2 / 0$ Dexon is used to approximate the full thickness of the adjacent edges followed by an outer seromuscular layer of interrupted Dexon sutures. In this way a pouch consisting of three segments of ileum each about $8 \mathrm{~cm}$ long is created; $5 \mathrm{~cm}$ of ileum projects distal to the pouch. The procedure is not difficult as no attempt is made to create a valve.

An assistant remains by the abdominal incision and the surgeon then takes up a position seated facing the perineum. An anal retractor is passed and the entire rectal mucosa removed in strips from the dentate line up to the top of the divided rectum. This dissection is made possible by injecting the submucosa with a solution of adrenaline in physiological saline ( 1 in 200000 ) to raise the mucosa off the underlying muscle. It is then relatively easy, using sharp scissor dissection, to remove it. The abdominal operator then passes the terminal ileum and distal half of the pouch down through the rectal stump; if the rectum is narrow or stenosed the muscle wall may be divided anteriorly as far downwards as is necessary. The free edges of the ileum are grasped by the perineal operator and drawn through the anus. An ileoanal anastomosis is then created at the level of the

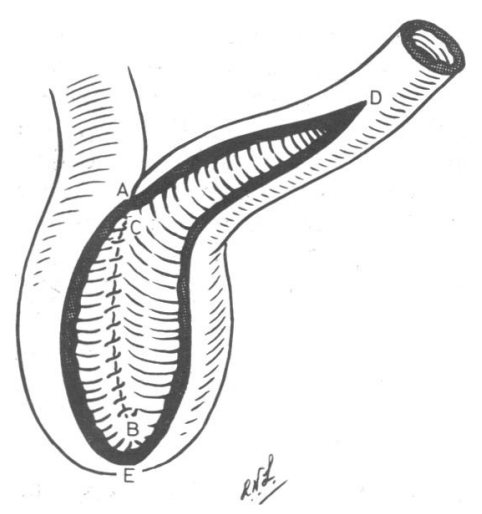

FIG 1 -Construction of ileal pouch from terminal $30 \mathrm{~cm}$ of small intestine. $\mathrm{B}, \mathrm{C}, \mathrm{E}$, and the mid-point between $\mathrm{D}$ and $\mathrm{E}$ are points of folding. $\mathrm{ABC}$ is the first fold. The final two folds will be complete when $D$ and $E$ are approximated.

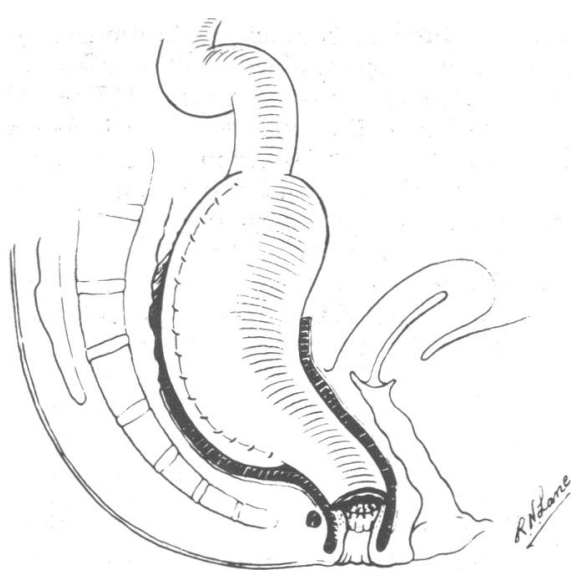

FIG 2-Appearances of completed operation.

dentate line using the per-anal route. Interrupted sutures of $3 / 0$ Dexon are used, each incorporating not only mucosa of the dentate line but a deep bite of the internal sphincter and full thickness of the wall of the terminal ileum. A defunctioning loop ileostomy is fashioned. Two pelvic drains are inserted, one from above and the other through the perineum. A large-gauge catheter is passed through the anus into the pouch and fixed by a suture to the perianal skin. The abdomen is closed. The completed operation is shown in fig 2 .

Postoperatively the catheter is left on continuous drainage. This and the urinary catheter are removed during the fifth to seventh postoperative days. The patient is then instructed to pass a Kock catheter per anum into the pouch at three-hour intervals during the day, the pouch being left on free drainage at night. The intervals between catheterisation may be extended according to the patient's tolerance.

\section{Patients}

The table gives brief details of the five patients available for study. A further three patients underwent the operation but were awaiting closure of their ileostomies. All were unsuitable for colectomy with ileorectal anastomosis for technical reasons. In cases 1,2 , and 4 a strong antipathy to a permanent abdominal ileostomy was the reason for performing the operation. In case 3 it was carried out for social reasons, and in case 5 because it was considered that the patient, who had Charcot-Marie-Tooth disease, would be unable to manage an ileostomy.

\section{Results}

\section{COMPLICATIONS}

There were no deaths. The postoperative course of the pouch procedure in cases 4 and 5 was uneventful. Two patients (cases 1 and ( 3 developed a pelvic abscess, which was drained through the anastomo- 
Details of five patients available for assessment after closure of temporary ileostomy

\begin{tabular}{|c|c|c|c|c|c|c|c|}
\hline \multirow{2}{*}{$\begin{array}{l}\text { Case } \\
\text { No }\end{array}$} & \multirow{2}{*}{$\begin{array}{l}\text { Sex and } \\
\text { age }\end{array}$} & \multirow{2}{*}{$\begin{array}{l}\text { Year of } \\
\text { onset of } \\
\text { disease }\end{array}$} & \multirow{2}{*}{$\begin{array}{l}\text { Date of } \\
\text { operation }\end{array}$} & \multirow{2}{*}{ Complications } & \multirow{2}{*}{$\begin{array}{l}\text { Months of } \\
\text { follow-up after } \\
\text { closure of } \\
\text { ileostomy }\end{array}$} & \multicolumn{2}{|c|}{ Function } \\
\hline & & & & & & Evacuation & Incontinence \\
\hline 1 & M 39 & 1973 & 9 July 1976 & $\begin{array}{l}\text { Pelvic abscess; partial anastomotic dehiscence; } \\
\text { anastomotic stenosis responding to dilatation }\end{array}$ & 9 & $\begin{array}{l}\text { Catheter, } 4 \text { times } \\
\text { daily }\end{array}$ & No \\
\hline 2 & M 24 & 1972 & 21 Feb 1977 & $\begin{array}{l}\text { Chest infection; small-bowel obstruction } \\
\text { (laparotomy, division of adhesions) }\end{array}$ & 3 & $\begin{array}{l}\text { Catheter, } 5-7 \text { times } \\
\text { daily }\end{array}$ & No \\
\hline 3 & F 19 & 1969 & 4 April 1977 & Pelvic abscess & 3 & Spontaneous, 2-3 & No \\
\hline 4 & M 33 & 1967 & 15 April 1977 & None & $2^{*}$ & Catheter, 5-6 times & Slight \\
\hline 5 & F 38 & 1972 & 16 Nov 1977 & None & 1 & $\begin{array}{l}\text { Catheter, 6-8 times } \\
\text { daily }\end{array}$ & Slight at night \\
\hline
\end{tabular}

*Pouch removed two months after closure of ileostomy.

sis and perineal drain site respectively. A clinically detectable defect in the anastomosis was observed only in case 1 . The subsequent stricture responded to dilatation. In case 2 the patient developed a chest infection immediately after the operation and small-bowel obstruction due to adhesions two months later. After laparotomy he made an uneventful recovery.

\section{FUNCTION}

The duration of follow-up after closure of the ileostomy ranged from one to nine months. When last seen, four of the patients had obtained a good result. They were well satisfied with the operation, not only because of their improved health, increased weight, and general well-being but also with respect to the functional outcome. Pressure in the perineum, apparently similar to the normal feeling, is the signal to empty the pouch. Estimations of pouch volume made from contrast enema examinations in cases 1,2 , and 3 ranged from 300 to $600 \mathrm{ml}$ (fig 3).

In case 3 spontaneous evacuation was occurring four or five times a day, the patient not needing to pass a catheter at all. In case 1 the patient catheterised the pouch two to four times during the day. The stool was semi-formed and he suffered no urgency. In case 2 the patient passed the catheter four to seven times a day. He experienced some urgency on occasions, especially when the stool was liquid. These patients could last throughout the night without needing to void. In case 5 , one month after closure of the ileostomy the patient was passing the catheter six to eight times a day. Minor faecal incontinence at night and urgency, which troubled her for the first two weeks, later improved.

The outcome in case 4 was unsuccessful. Technically both the construction of the pouch and closure of the ileostomy were satisfactory. After the ileostomy was closed, however, the patient had

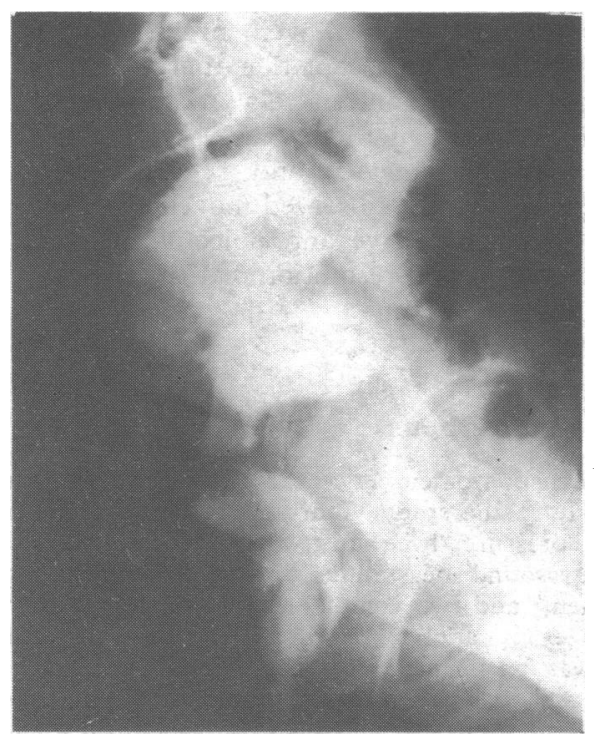

FIG 3-Contrast-enema radiograph of pouch. difficulty in passing the catheter and suffered from tenesmus, faecal soiling, and a frequent desire to evacuate the pouch. These problems were overcome by a postanal repair of the pelvic floor to restore the angle between pouch and anal canal. Three weeks later he could tolerate intervals of four to five hours between catheterisations. He was not prepared to continue self-catheterisation, however, having developed an aversion to the procedure. On his insistence the pouch was removed and a terminal ileostomy fashioned on 20 August 1977. He recovered well and when seen one month later was in good health.

There was no obvious metabolic derangement in these patients after closure of the ileostomy. Details of the biochemical values will be given later.

\section{Discussion}

Total excision of the colon and rectal mucosa with conservation of the anal sphincter is not a new procedure. Nissen (1933) is reputed to have been the first to describe a proctocolectomy with ileoanal anastomosis, ${ }^{8}$ and there have been several reports of its use in ulcerative colitis. ${ }^{15-18}$ A successful functional result occurred in only $40 \%$ of these cases. ${ }^{8}$ More recently a technique was described in which ileorectal continuity was restored after removal of the rectal mucosa by curettage ${ }^{9}{ }^{10}$ Out of 12 patients so treated, seven were said to be leading normal lives, ${ }^{10}$ although no detailed information on function was given. The rectal mucosa appeared to regenerate after this procedure and it therefore seems likely to be subject to the same risks as occur after ileorectal anastomosis.

Valiente and Bacon ${ }^{8}$ constructed a double-loop pouch in dogs that was anastomosed end to end to the anal canal. Two animals survived with satisfactory bowel function. Kock later showed that an ileal reservoir is feasible in man. ${ }^{11}$. Continence is maintained by means of an inverted nipple valve of ileum distal to the pouch. There is now considerable experience of this operation, and out of 138 patients followed up by Kock, ${ }^{3} 90$ did not need to wear an ileostomy appliance. These results, however, were not matched by others, ${ }^{12}$ and the technical problems arising from this approach to reconstructive surgery are in large part due to the valve.$^{1-3}$ Hence we decided to create a pouch without a valve and to rely on the sphincter mechanism to maintain continence.

The results were possibly better than expected, with four out of five patients well satisfied with the outcome. It would naturally be desirable for the patient to be able to defecate spontaneously and the reason why catheterisation is necessary is not clear. The length of the ileum between the pouch and anastomosis may be important. With further experience, however, we hope that the factors enabling spontaneous evacuation to occur will become clear. The detailed results of physiological studies on these patients will be reported separately. The lower rectum is not mobilised in this operation for three reasons. Firstly, damage to the nerves supplying the pelvic floor, bladder, and generative organs is avoided. Secondly, the muscles of the pelvic floor are left undisturbed. Thirdly, the risk of a pelvic haematoma and therefore pelvic sepsis is reduced. Great importance is attached to the last factor because an 
abscess, besides causing morbidity, may impair the functioning of the pelvic floor.

The importance of temperament when selecting patients is well shown by case 4 . Although the operation was technically uncomplicated and the patient obtained satisfactory function (after initial difficulties), he was unable to cannulate the pouch for psychological reasons. In retrospect probably he was unsuited to the procedure from the start; however, such an assessment is difficult to make preoperatively.

It must be emphasised that the colonic and rectal mucosa, which in ulcerative colitis is alone the site of the disease, is totally eliminated by this operation, the risk of further inflammation and of malignant change thus being removed. Therapeutically, therefore, it is as effective as proctocolectomy. Moreover, there has been no indication that operative risk and complications will be greater than in any other major pelvic operation. The severity of the disease in the rectum is of no great importance; the procedure may be carried out in the presence of ulceration, stenosis, or even a rectovaginal fistula. An adequate anal sphincter mechanism is, however, necessary.

Provided these initial results are maintained and reproducible this operation may offer a satisfactory alternative to proctocolectomy with a permanent ileostomy. Even at this early stage it seems desirable for it to be known that preservation of anal function is feasible. The plea is therefore made that the rectum be retained when operating for colitis so that the patient may be given a chance, should he wish it, to lose his ileostomy. It would, however, be wise in the first instance to confine this procedure to those who have an active antipathy to an ileostomy. They will be prepared to pay the price of any initial difficulties that may occur in order to avoid a stoma.

Requests for reprints should be addressed to: Sir Alan Parks, St Mark's Hospital, City Road, London EC1V 2PS.

\section{Addendum}

Two of the patients awaiting closure of the ileostomy have now had the operation. The early results are good. A patient with familial polyposis and carcinoma of the upper rectum has also been treated with an excellent functional result. In this case the indication was again total refusal to accept a permanent ileostomy.

\section{References}

${ }^{1}$ Goligher, J C, and Lintott, D, British fournal of Surgery, 1975, 62, 893.

${ }^{2}$ Beahrs, O H, Diseases of the Colon and Rectum, 1976, 19, 192.

${ }^{3}$ Kock, N G, Diseases of the Colon and Rectum, 1976, 19, 200.

${ }^{4}$ Jones, P F, Munro, A, and Ewen, S W B, British Fournal of Surgery, 1977 64, 615 .

5 Aylett, S, Archives Françaises des Maladies del'Appareil Digestif, 1974, 63, 585.

${ }^{6}$ Adson, M D, Cooperman, A M, and Farrow, G M, Archives of Surgery, 1972, 104, 424.

' Grüner, O P N, et al, Scandinavian fournal of Gastroenterology, 1975, 10, 641.

${ }^{8}$ Valiente, M A, and Bacon, H E, American fournal of Surgery, 1955, 90, 742.

${ }^{9}$ Oppolzer, R, Diseases of the Colon and Rectum, 1964, 7, 537.

${ }^{10}$ Hampton, J M, Diseases of the Colon and Rectum, 1976, 19, 133.

${ }^{11}$ Kock, N G, Archives of Surgery, 1969, 99, 223.

12 Parks, A G, in Clinical Surgery-Abdomen, Rectum and Anus, ed C Rob, $\mathrm{R}$ Smith, and C N Morgan, p 545. London, Butterworths, 1966.

13 Jeffery, P J, Hawley, P R, and Parks, A G, British fournal of Surgery, 1976, 63, 678 .

${ }^{14}$ Parks, A G, Proceedings of the Royal Society of Medicine, 1972, 65, 47.

15 Ravitch, M M, Surgery, 1948, 24, 170.

${ }_{16}$ Devine, A, Surgery, Gynecology and Obstetrics, 1951, 92, 437.

17 Best, R R, fournal of the American Medical Association, 1952, 150, 637.

18 Drobni, A, Diseases of the Colon and Rectum, 1964, 7, 416.

(Accepted 28 April 1978)

\title{
Comparison between subjective and ultrasound assessments of fetal movement
}

\author{
A GETTINGER, A B ROBERTS, S CAMPBELL
}

British Medical fournal, 1978, 2, 88-90

\section{Summary and conclusions}

Forty pregnant women participated in a study to compare subjective with ultrasound assessments of fetal movements. A real-time ultrasound scanner was used. Movements were recorded for 45 minutes in all cases. There was a significant positive correlation between the number of movements recorded by the two methods, but the $95 \%$ confidence limits were wide and no correlation was found in those patients who recorded fewer than 20 movements in the study period. Thus "false-positive" information may be obtained from purely subjective data, and in patients reporting low "kick counts" fetal activity should be assessed from real-time ultrasound recordings.

\footnotetext{
Department of Obstetrics and Gynaecology, King's College Hospital Medical School, London SE5 8RX

A GETTINGER, BSC, research assistant (now medical student, Dartmouth Medical School, Hanover, New Hampshire, USA)

A B ROBERTS, MB, MRCOG, Rank research fellow

$S$ CAMPBELL, MB, FRCOG, professor
}

\section{Introduction}

The mother's assessment of fetal movement is used to indicate fetal wellbeing. ${ }^{1-5}$ Pearson and Weaver ${ }^{2}$ and Sadovsky et $a l^{1}{ }^{1}$ equated low counts of fetal movement with poor fetal outcome, and most workers now accept that there is a good correlation between the true amount of fetal movement and the "kick counts" noted by the mother. ${ }^{6}$ Sadovsky et al used an electromagnetic measuring device and reported that on average patients felt $87 \%$ of the observed movements. We have carried out a study of subjective and objective assessments of fetal movement using a good-resolution real-time ultrasound scanner. We report here the results.

\section{Patients and methods}

Forty pregnant women between 25 and 40 weeks' gestation agreed to participate in the study. Thirty were clinically normal, five had raised blood pressure, three had growth-retarded fetuses as determined by serial ultrasound measurement of the circumferences of the head and abdomen, ${ }^{7}$ and two complained of diminished fetal movement. Ultrasound examination using an ADR real-time scanner (Tempe, Arizona) was performed with the patient semi-recumbent. The transducer was positioned to include a transverse section of the fetal trunk and both legs and held in place with a Kretz Technic clamp. In this way we observed most of the fetal movements, though 